\title{
Molecular cloning of a hyaluronidase from Bothrops pauloensis venom gland
}

Letícia Eulalio Castanheira ${ }^{1,4}$, Renata Santos Rodrigues ${ }^{1,4^{*}}$, Johara Boldrini-França ${ }^{2}$, Fernando PP Fonseca ${ }^{3}$, Flávio Henrique-Silva ${ }^{3}$, Maria I Homsi-Brandeburgo ${ }^{1}$ and Veridiana M Rodrigues ${ }^{1,4}$

\begin{abstract}
Background: Hyaluronate is one of the major components of extracellular matrix from vertebrates whose breakdown is catalyzed by the enzyme hyaluronidase. These enzymes are widely described in snake venoms, in which they facilitate the spreading of the main toxins in the victim's body during the envenoming. Snake venoms also present some variants (hyaluronidases-like substances) that are probably originated by alternative splicing, even though their relevance in envenomation is still under investigation. Hyaluronidases-like proteins have not yet been purified from any snake venom, but the cDNA that encodes these toxins was already identified in snake venom glands by transcriptomic analysis. Herein, we report the cloning and in silico analysis of the first hyaluronidase-like proteins from a Brazilian snake venom.
\end{abstract}

Methods: The cDNA sequence of hyaluronidase was cloned from the transcriptome of Bothrops pauloensis venom glands. This sequence was submitted to multiple alignment with other related sequences by ClustalW. A phylogenetic analysis was performed using MEGA 4 software by the neighbor joining (NJ) method.

Results: The cDNA from Bothrops pauloensis venom gland that corresponds to hyaluronidase comprises $1175 \mathrm{bp}$ and codifies a protein containing 194 amino acid residues. The sequence, denominated BpHyase, was identified as hyaluronidase-like since it shows high sequence identities (above 83\%) with other described snake venom hyaluronidase-like sequences. Hyaluronidases-like proteins are thought to be products of alternative splicing implicated in deletions of central amino acids, including the catalytic residues. Structure-based sequence alignment of BpHyase to human hyaluronidase hHyal-1 demonstrates a loss of some key secondary structures. The phylogenetic analysis indicates an independent evolution of BpHyal when compared to other hyaluronidases. However, these toxins might share a common ancestor, thus suggesting a broad hyaluronidase-like distribution among venomous snakes.

Conclusions: This work is the first report of a cDNA sequence of hyaluronidase from Brazilian snake venoms. Moreover, the in silico analysis of its deduced amino acid sequence opens new perspectives about the biological function of hyaluronidases-like proteins and may direct further studies comprising their isolation and/or recombinant production, as well as their structural and functional characterization.

Keywords: Alternative splicing, Hyaluronidase-like, Snake venom

\footnotetext{
* Correspondence: rsrodrigues@ingeb.ufu.br

${ }^{1}$ Instituto de Genética e Bioquímica, Universidade Federal de Uberlândia, Uberlândia, MG CEP 384000-902, Brasil

${ }^{4}$ National Institute of Sciences and Technology on Nanobiopharmaceutics (INCT), Federal University of Minas Gerais (UFMG), Belo Horizonte, Minas

Gerais State, Brazil

Full list of author information is available at the end of the article
}

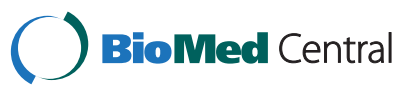

(c) 2014 Castanheira et al.; licensee BioMed Central Ltd. This is an Open Access article distributed under the terms of the Creative Commons Attribution License (http://creativecommons.org/licenses/by/2.0), which permits unrestricted use, distribution, and reproduction in any medium, provided the original work is properly credited. The Creative Commons Public Domain Dedication waiver (http://creativecommons.org/publicdomain/zero/1.0/) applies to the data made available in this article, unless otherwise stated. 


\section{Background}

"Hyaluronidase" is a term introduced by Meyer [1] to denote any enzyme that degrades hyaluronate. These enzymes are present in human testis, spleen, skin, eye, liver, kidney, uterus, placenta, tear, blood and sperm [2]. Hyaluronidases from many animal classes usually share common structural features, conserving all the critically important sites for enzyme activity [3]. Hyaluronidases were identified at first in bovine testis and in bacteria and were subsequently described as "spreading factors" $[4,5]$.

Hyaluronidases are often found in a diversity of venoms, such as those from snakes, lizards and arthropods (scorpions, spiders, wasps and bees), in which they act as an immunogen. In snake venoms, this enzyme potentiates the toxicity and contributes to local damage at the bite site by affecting the extracellular matrix integrity due to hyaluronate degradation [6-8].

There are also some hyaluronidase variants, known as hyaluronidase-like proteins, which are products of alternative splicing [9]. These truncated forms of hyaluronidases have been recently identified in snake and bee venoms and in human serum as well $[3,10,11]$. Ever since, some questions have been raised about their physiological role. A hyaluronidase-like isoform from Vespula vulgaris venom was hypothesized to act as a lectin by binding to hyaluronate and/or other related substances without degrading them [11].

The isolation and biological characterization of hyaluronidases from snake venoms, including Bothrops genus, are usually difficult to achieve due to their instability and fast degradation, and because of their relatively low concentration in these biological samples. However, the purification of hyaluronidases from Naja naja, Agkistrodon contortrix contortrix, Cerastes cerastes and Crotalus durissus terrificus venoms has already been reported [12-15]. In the present work, we describe the molecular cloning and in silico analysis of a cDNA sequence that encodes a hyaluronidase-like protein from the Bothrops pauloensis venom gland. The sequence was compared to other known hyaluronidase-like sequences in order to screen conserved structural features, which may generate perspectives regarding its potential physiological functions and contributions to the envenoming.

\section{Methods}

Isolation of CDNA hyaluronidase from Bothrops pauloensis venom gland

A venom gland from a B. pauloensis adult snake was dissected three days after venom extraction, when transcription is most stimulated [16]. A cDNA library from Bothrops pauloensis venom gland, formerly referred to as Bothropoides pauloensis, was previously constructed by Rodrigues et al. [17]. Briefly, the pair of venom glands was homogenized by liquid nitrogen and the total RNA was extracted by the Trizol method (Invitrogen, UK). The mRNA was purified from total RNA by using PolyATract ${ }^{\circ}$ mRNA Isolation kit (Promega, USA) and the cDNA library was obtained by CloneMiner cDNA Library Construction kit (Invitrogen, UK) with $3 \mu \mathrm{g}$ of purified mRNA. First and second cDNA strands were synthesized as described by the manufacturer protocols whereas size fractioning of cDNA was carried out in a $1 \mathrm{~mL}$ column previously packed with Sephacryl S-500 resin. The cDNA was precipitated with ethanol and then resuspended in $50 \mathrm{~mL}$ of milli-Q water and submitted to Polymerase Chain Reaction (PCR). The PCR products were purified and sequenced using DYEnamic ET Terminator Cycle Sequencing kit (GE Healthcare, UK) on a MEGA-BACE 1000 automated DNA sequencer (GE Healthcare, UK).

After the cDNA sequencing, specific primers were designed in order to certify that the full open reading frame (ORF) was obtained. The specific primers were Hyase internal forward (5'-TTGGTGAAACAGCGGCCATG-3') and Hyase internal reverse (5'-CTTTTCATCCAGCA CAATAC-3'). After amplification, the PCR products were analyzed by electrophoresis on $1 \%$ agarose gel. The bands containing the PCR products were purified from gel using the Wizard SV Gel and PCR clean up system kit (Promega, Brazil), according to the manufacturer's specifications. The Ins T/A clone PCR Product kit (Fermentas, Lithuania) was used for rapid cloning of PCR products in pTZ57R/T plasmids. Bacteria colonies were selected on a medium containing ampicillin, IPTG and X-Gal. The recombinant colonies were analyzed by PCR and gel electrophoresis. PCR products were purified and submitted to sequencing using DYEnamic ET Terminator Cycle Sequencing Kit (GE Healthcare, UK) on a MEGABACE 1000 automated DNA sequencer (GE Healthcare, UK). The software Base Caller Cimarron 3.12 was used to analyze the electropherograms and generate sequences, which were then aligned in the software Bioedit version 7.0.5.3.

\section{In silico analysis of CDNA sequences}

Hyaluronidase sequences were searched against the NCBI database (http://www.ncbi.nlm.nih.gov/). BLASTp 2.2.19 was used for scoring the sequence alignments and the maximum e-value obtained was $2 \mathrm{e}^{-100}$ [18]. The predicted sequence of hyaluronidase from Bothrops pauloensis venom and other full-length hyaluronidases and hyaluronidase-like sequences from the database were aligned by ClustalW (available in http://www.ebi.ac.uk/Tools/clustalw2/index. html). The putative glycosylation sites were identified by the glycosylation prediction software NetNGlyc (http:// www.cbs.dtu.dk/services/NetNGlyc/). Predicted signal peptide cleavage site was determined by the SignalP algorithm [19]. The theoretical isoelectric point and molecular mass were computed using the tool ProtParam [20]. 


\section{Phylogenetic tree}

Sequences were aligned by ClustalW algorithm and the phylogenetic analysis was performed using the software MEGA 4 by the neighbor joining (NJ) method [21]. The evolutionary distances were computed by the JTT matrixbased method. The reliability of NJ trees was evaluated by analyzing 1000 bootstrap replicates. Human hyaluronidase (NP009296.1) was employed as an out-group.

\section{Results and discussion}

Since snakes need to kill their prey quickly and efficiently, a systemic delivery of the main venom toxins is required in order to potentiate the lethal effects. Thus, these toxins enter into the circulatory system of the victim with the aid of toxins that degrade the extracellular matrix (ECM) (metalloproteinases, myotoxic phospholipases $\mathrm{A}_{2}$ and hyaluronidases) [10]. Hyaluronidases have been identified in some snake venoms, such as those from Agkistrodon acutus, Naja naja, Vipera russelli siamensis, Trimeresurus flavoviridis, Trimeresurus popeorum, Trimeresurus macrops, Trimeresurus albolabris, Agkistrodon contortrix contortrix and Crotalus durissus terrificus [6,15,22-24].

In this study, we present the amino acid sequence of a hyaluronidase-like (BpHyase) protein deduced from a cDNA obtained from $B$. pauloensis venom gland transcriptome [17]. Interestingly, the identification of a single truncated hyaluronidase-encoding EST was achieved in an attempt to clone true hyaluronidase, which may reflect its low representation in the venom when compared to other toxin classes. On the other hand, most snake venom-gland transcriptomes reveal the presence of transcripts corresponding to hyaluronidase [10,25].

The cDNA sequence of hyaluronidase from B. pauloensis gland, denominated BpHyase, is composed of $1175 \mathrm{bp}$ and codifies 194 amino acid residues for the mature protein, including eight cysteine residues (Figure 1). The fulllength sequence of BpHyase comprises an ORF of $582 \mathrm{bp}$, flanked by a 5' UTR of $100 \mathrm{bp}$ and a 3' UTR of $493 \mathrm{bp}$. The initiating methionine of BpHyase is followed by a predicted signal peptidase I (SPase I) cleavage site at FNG20$\mathrm{VH}$, which is consistent with the secreted nature of toxins. This prepeptide is believed to initiate the transport of preBpHyase into the endoplasmatic reticulum for glycosylation and is characterized by an $\mathrm{N}$-terminal basic region (Met1-Lys7), a hydrophobic region (Cys8-Phe14) and a polar C-terminal (Leu15-Gly20) [26]. The presence of a prepeptide followed by a start codon indicates that BpHyase is probably translated into protein. Moreover, this prepeptide probably releases a mature protein that, after cleavage, possesses 174 amino acids with a theoretical pI of 9.60 and molecular mass of 19,892.3 Da. Therefore, this prepeptide may act as a signal sequence that directs the protein to the secretory pathway of venom gland cells [25].
The presence of $\mathrm{N}$-linked glycans is supposed to be necessary for the stabilization of intramolecular folding and the consequent retention of enzymatic activity. Furthermore, changes in glycosylation are likely responsible for the diversity of biological functions exhibited by protein isoforms [27]. In relation to BpHyase, several asparagine residues identified in its sequence could potentially constitute glycosylation sites, thus influencing some physical and chemical parameters of the molecule. The glycosylation prediction algorithm (NetNGlyc) indicated the following glycosylation sites for BpHyase: N101, V102, T103 and N146, A147 and T148 (Figure 2). The glycosylation consensus triad is NXS or $\mathrm{T}$, where $\mathrm{X}$ represents any amino acid, except proline $[28,29]$. However, further structural analyses are of great importance to reveal the residues truly involved in glycosylation.

Three cDNA variants of truncated hyaluronidase from Echis pyramidum leakeyi, Echis carinatus sochureki and Bitis arietans venom glands were already identified: Hy-L1000 that encodes the consensus amino- and carboxytermini with a central deletion of 256 residues, Hy-L-750 that lacks the consensus amino-terminus and Hy-L-500 that lacks the amino-terminus and encodes a shorter carboxy-terminal segment [10]. Hy-L-1000 is probably translated into a protein without enzymatic activity, while Hy-L-750 and Hy-L-500 represent non-translated transcripts due the absence of an essential translation initiating motif. The inferred protein-coding sequence of BpHyase was classified into the Glycol-Hydro-56 superfamily by protein BLAST analysis, and the highest identity (88\%) was presented by truncated hyaluronidase from Echis carinatus sochureki venom (GenBank: ABI33950) (Figure 2). In order to confirm its identity, BpHyase was aligned by ClustalW algorithm against other reported hyaluronidase-like sequences from snake venoms, in which the highest sequence identities (above 86\%) were observed for Hy-L-1000 truncated hyaluronidases, revealing that BpHyase presents the same residue deletion pattern as these molecules.

It would be tempting to speculate that partial hyaluronidases or hyaluronidases-like proteins represent vestigial enzymes with no activity, since some authors affirmed they lack catalytic residues because of deletions of central residues during their evolutionary history [10,30,31]. The predicted BpHyase amino acid sequence was aligned with other full-length and truncated hyaluronidases from snake venoms, as well as human hyaluronidase (hHyal-1), in order to investigate its deletion pattern (Figure 3). The multiple alignment revealed a substantial deletion of 255 amino acids, starting at residue 52, resulting in the loss of two cysteines, the catalytic (Glu135) and positional residues (Asp133, Tyr206, Tyr253) from full-length viper hyaluronidases. Structural data, site-directed mutagenesis and 


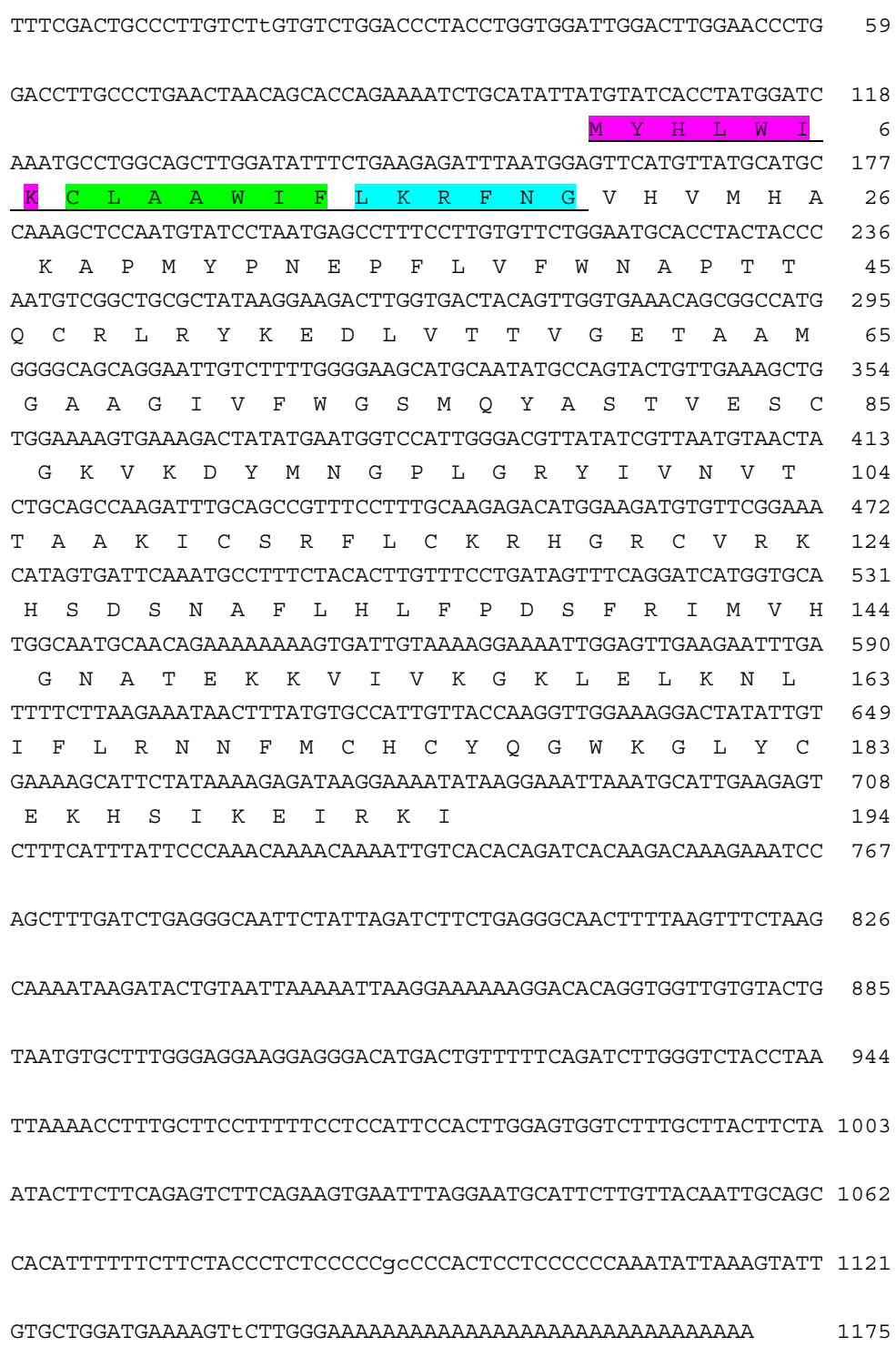

Figure 1 Full-length nucleotide and deduced amino acid sequence of BpHyase. The underlined amino acids indicate the inferred sequence of signal peptide which is characterized by an N-terminal basic region, marked in pink, a hydrophobic region (green) and a polar C-terminal (light blue) The nucleotide and amino acid sequences reported herein are available in GenBank with accession numbers GR955246 and FJ654998.1, respectively.

steady state enzyme kinetics allowed the determination of some important residues for human Hyal-1 catalysis [32].

An essential direct role in chemical catalysis was suggested for Glu131 and a supporting role for Asp129, which was also observed by Arming et al. [33]. In these cases, the acidic character of the residues is critical for enzymatic activity while Glu131 acts as a proton donor to the hydroxyl group in glycosidic cleavage. These acid residues are also conserved into hyaluronidases from Trichoderma reesei (Glu212 and Glu217), Bacillus agaradherans (Glu139 and Glu228), Echis ocellatus venom (Asp133 and Glu 135), as well as in those from bovine testis PH20 (Asp147 and Glu 149) and Apis mellifera venom (Asp111 and Glu113) [34-37,10]. Moreover,
Tyr202 and Tyr247 are also essential residues for catalytic activity, since Tyr202 probably binds the substrate and Tyr247 is suggested as coordinating and stabilizing the oxidation during transition state formation [32].

Figure 3 also indicates that BpHyase encodes a protein containing the consensus amino and carboxi-termini, as well as Hy-L-1000 truncated hyaluronidase variants from E. c. sochureki and Bitis arietans venoms. hHyal-1 human hyaluronidase showed a cross-generic sequence conservation of $38 \%$ when compared to BpHyase, representing the most similar hyaluronidase that had its structure solved. The alignment of hHyal-1 to BpHyase allowed the mapping of the secondary structures lost by deletions and demonstrated the lack of regions that are 


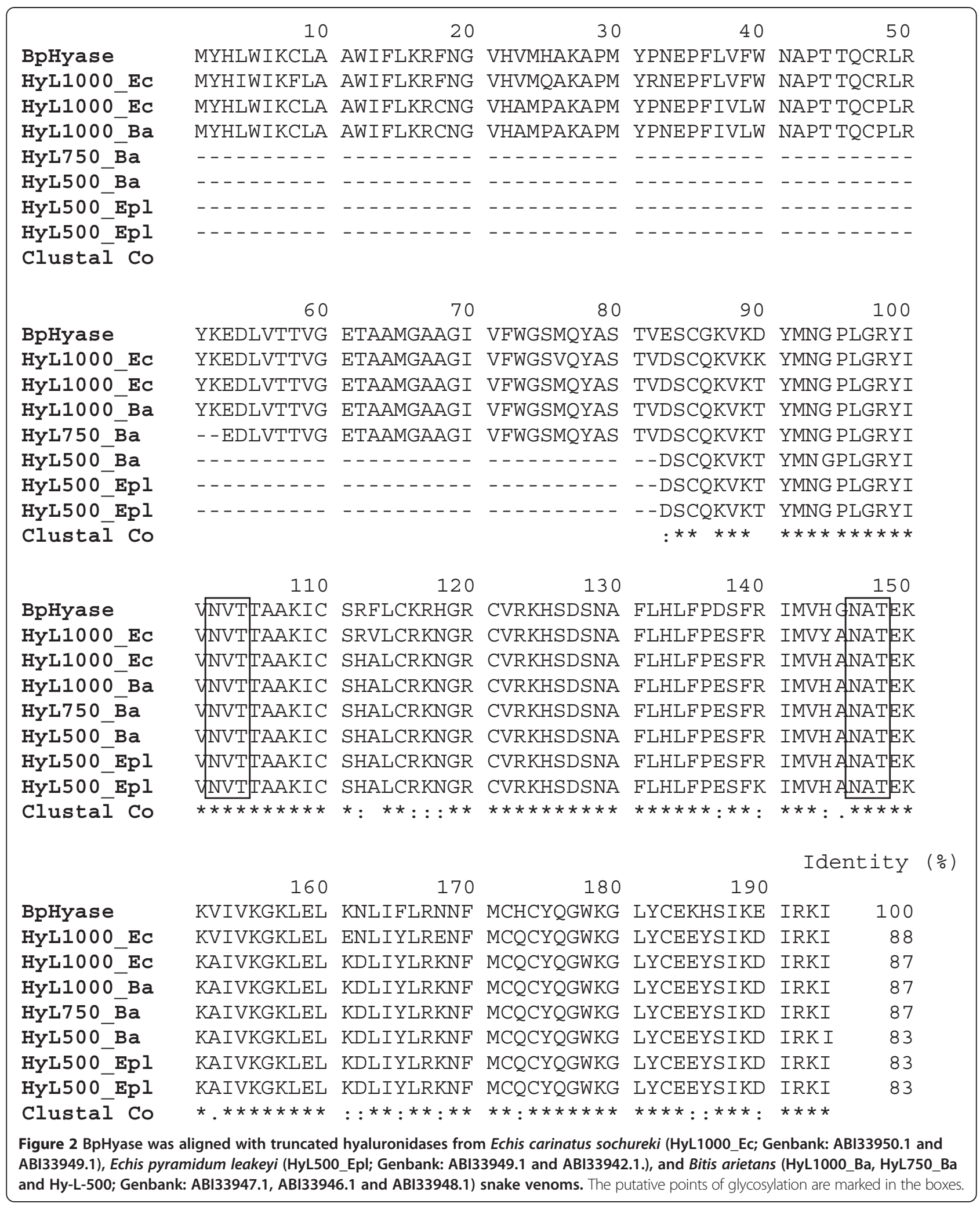

probably involved in the formation of $\beta$-strands 2 to 7 and $\alpha$-helices 2 to 6 . The crystal structures of bee venom (bvHyal) and human (hHyal-1) hyaluronidases reveal a classical $(\beta / \alpha)_{8}$ TIM barrel fold, which is common to many hydrolases $[36,38,39]$. In bvHyal, the barrel is formed by only seven strands $(\beta 1-\beta 7)$, in contrast to 


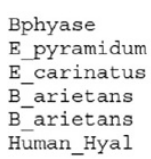

VHVMHAKAPMY PNEPFLVFWNAPTTOCRLRYK- $\ldots \ldots \ldots$ VHVMOAKAPMYRNEPFLVFWNAPTTOCRLRYKVDLDLKTFHIVSNANDSLSGSAVTIFYP 60 VHAMPAKAPMYPNEPFIVLWNAPTTOCPLRYK VHAMPAKAPMYPNEPFIVLWNAPTTOCPLRYKVDLDLKTFHIVANPNDSLSGSVVTI FYP 60 VHAMPAKAPMYPNEPETVLWNAPTTCCPLRYK - . . . . . . . . . . . . . - - -RSFRGPLI PNRPETTVWNANTOWC BRHGVDVVSVRVVANPGOTERGPDMTIFYS 57

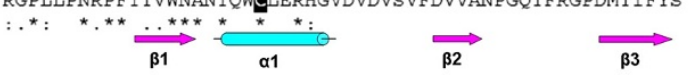

(-1) NHLGVYPHIDDRGHFFHGI I PQNESLTKHLNKSKSDINRI I PLKAFHGLGVIDWENWRPQ 120 NHLGVYPHIDERGHFFHGI I PONESLTKHLNKSKSDINRMI PLKT FHGLGVIDWENWRPO 120 SQLGTYPYYTPTGEPVFGGLPONASLIAHLARTFODILAAIPAPDFSGLAVIDWEAWRPR 117

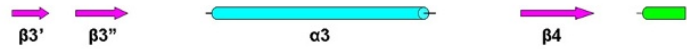
WDRNWGSKNVYRNRSIQFARDLHPELSEDKIRRLAKKEYEKAAKSFMRDTLLLAEEMRPD 180 WDRNWGSKNVYRNRS IQFAKELHPELSBDKIKRLAKKEYEKAAKSFMRDTLLLAEEMRPN 180 W. WAFNWDTKDIYRQRSRALVQAQHPDWPAPQVEAVAQDQFQGAARAWMAGTLQLGRALRPR 177
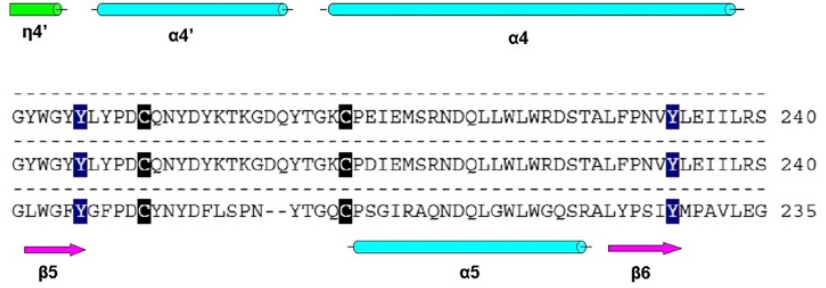

-EDLVTTVGTAM 45 SDNALKFVHHRLKEAMRIASMAREDYALPVFAYARPFYAYTFEPLTOEDLVTTVGETAAM 300 - EDLVTTVGTAMM 45 SDNALKFVHHRLKESMRIASMAREDYALPVFVYARPFYAYTFEPLTQEDLVTTVGETAAM 300 (1) TGKSQMYVQHRVAEAFRVAVAAG-DPNLPVLPYVQIFYDTTNHFLPLDELEHSLGESAAQ 294
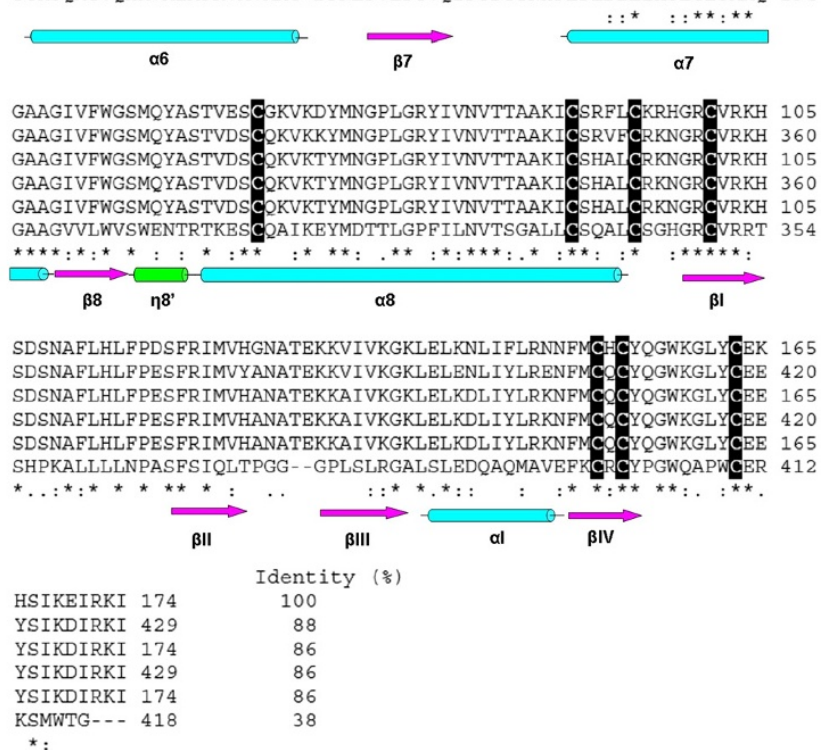

Figure 3 Structure-based sequence alignment of mature truncated and complete hyaluronidases. Full-length hyaluronidases from Echis pyramidum leakeyi (E_pyramidum; Genbank: ABI33941.1), Hy-L-1000 truncated hyaluronidase from Echis carinatus sochureki (E_carinatus; Genbank: ABI33950.1), full-length hyaluronidase from Bitis arietans (B_arietans; Genbank: ABI33945.1), Hy-L-1000 truncated hyaluronidase from Bitis arietans (B_arietans; Genbank: ABI33947.1) and human hyaluronidase (Human_hyal; Genbank: 2PE4). Key catalytic residue is shown in red and positional residues appear in blue. Cysteine residues are marked in black. Secondary structures were based on the human hyaluronidase crystal structure [38]. Secondary structure elements for human hyaluronidase are shown below the sequences: pink arrows represent $\beta$-strands, blue cylinders a-helices, and red cylinders $3_{10}$ helices. 
hHyal-1, which presents all the eight strands [36,38]. The alignment of BpHyase and other hyaluronidases and hyaluronidases-like prteins from snake venoms with hHyal-1 demonstrates that they lack the residues responsible for forming the $\beta$-strands 2 to 7 (Figure 3). This fact indicates that BpHyase and other snake venom hyaluronidases-like proteins have a different folding pattern than that described for hHyal-1 and bvHyal, although this does not necessarily imply a loss of biological activity during envenoming.

Alternative splicing is a molecular mechanism by which different combinations of exons can be alternatively linked in order to produce different mRNA isoforms. In the globular enzymatic proteins, such as hyaluronidase, a negative selection pressure operates against gene duplication and diversification, since their correct folding is generally more sensitive to mutations [40]. Therefore, alternative splicing is the most important source of functional diversity for globular proteins in eukaryotes [41,42]. Alternative splicing variants of hyaluronidases were previously described in hHyal-1 and hHyal-3 from human prostate cancer cell lines and Vespula vulgaris venom [11,43]. Moreover, researchers hypothesized that spliced variants would have their function silenced and demonstrated that some hyaluronidase splicing variants from bladder tumor tissues would form a complex with true hyaluronidases, displaying the spreading activity and, consequently, regulating the functional aspects of these true hyaluronidases by alternative mRNA splicing $[44,45]$. Therefore, spliced variants of hyaluronidases would provide a valuable tool for modeling a metastasis inhibitor. Nevertheless, the impact of alternative splicing needs to be further investigated in hyaluronidases from human and venoms, in order to screen a biotechnological application for these recently discovered enzymes. In the present work, we suggest that BpHyase would also operate in association with a true hyaluronidase from Bothrops pauloensis venom in order to potentiate its activity as a "spreading factor" during the envenoming.

In addition, it was supposed that hHyal-1 splice variants may play regulatory roles by binding to partner proteins via interaction with the carboxi-terminal HyalEGF-like domain, resulting in modulation of its enzymatic activity [38]. The EGF domain is present in many extracellular proteins and is involved in cell adhesion and cell-cell communication $[46,47]$. In mammalian hyaluronidases, the HyalEGF-like domain is characterized by an EGF disulfide bond signature sequence. The three disulfide bonds of the HyalEGF-like domain are possibly responsible for the maintenance of its fold even when the catalytic domain unfolds [38]. Mapping deletions on the BpHyase structure demonstrates that in BpHyal-1 the segment correspondent to the HyalEGF-like domain remains intact (Figure 3), which may confer regulatory roles on these hyaluronidase-like molecules. This result is in agreement with our hypothesis that BpHyase contributes to the spreading of the main toxins into the envenomed body of the victim. On the other hand, these findings have not previously been reported for snake venoms. In this conception, further studies concerning the isolation and/or heterologous expression of

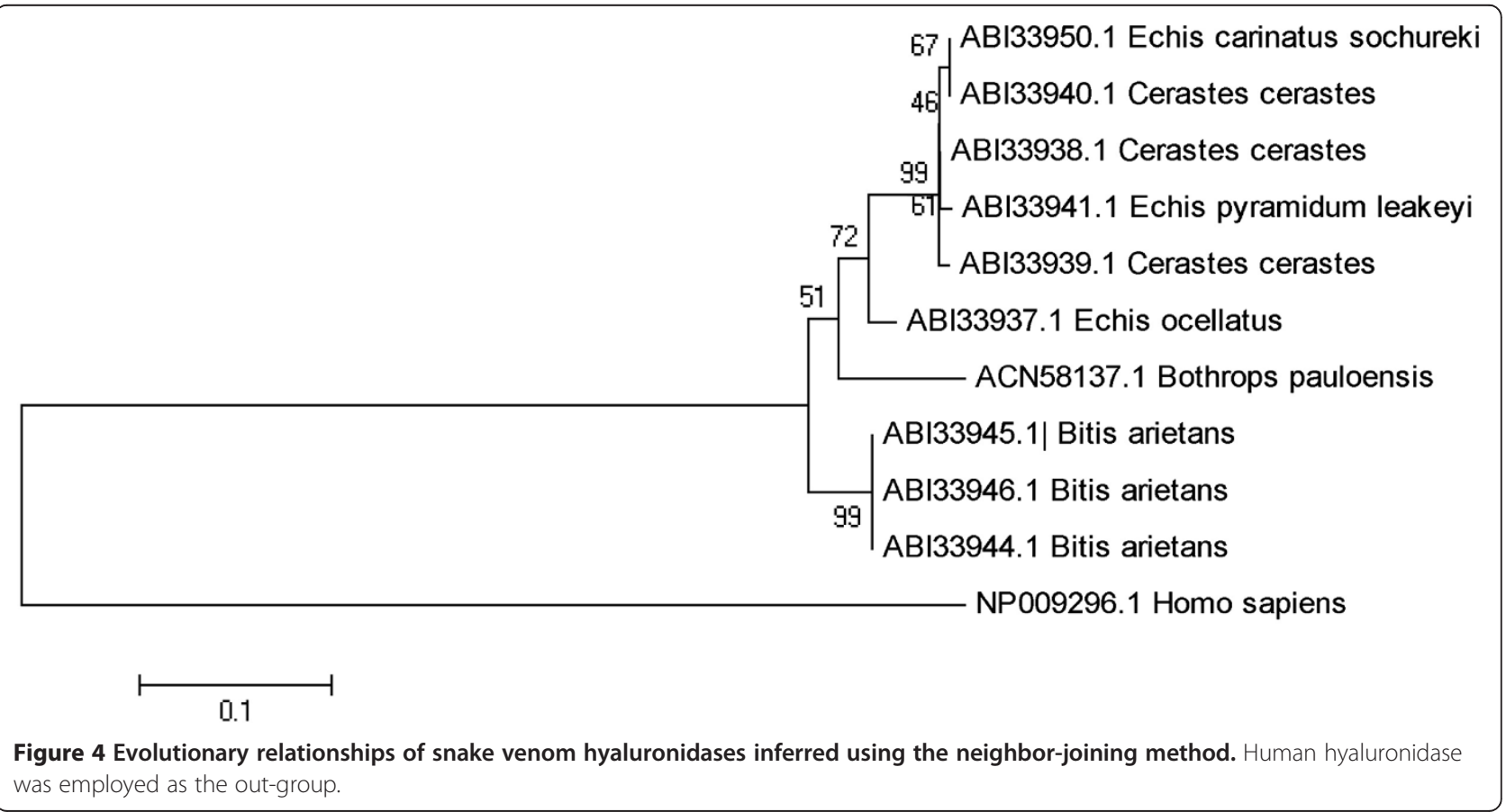


hyaluronidase-like toxins would be of great interest for testifying their biological role during envenoming.

The phylogenetic analysis of hyaluronidase-like sequence and true hyaluronidases from the Viperidae family (Figure 4) showed that these molecules form a monophyletic group, indicating a recent divergence among them. The branches amongst BpHyase and other hyaluronidases may be due to point mutations and/or gene duplication, which would result in new amino acid sequences. This approach is based on the description by Futuyma [48] in which the homologous genes from different species evolve at much higher rates than others, and also, when a single gene pool changes, it can evolve into new species. BpHyase was visualized in a separate branch, which indicates an independent evolution of this toxin when compared to hyaluronidases and hyaluronidases-like proteins from Bitis, Echis and Cerastis genders [49]. The most interesting observation is that hyaluronidases-like proteins are, until now, described only for Bothrops pauloensis, Echis carinatus and Bitis arietans venoms, which inhabit different continents. All these observations suggest that hyaluronidases-like proteins may share a common ancestor, thus presenting a broad distribution among venomous snakes.

\section{Conclusions}

Herein we have reported the first hyaluronidase-like cDNA sequence from a Brazilian snake venom. The in silico analysis of its deduced amino acid sequence opens new perspectives concerning its biological functions, suggesting a regulatory role that needs to be investigated. Moreover, this work may guide further studies comprising their isolation and/or recombinant production, as well as their detailed structural and functional characterization.

\section{Ethics committee approval}

Bothrops pauloensis was donated by the Reptile Sector of the Federal University of Uberlândia, Minas Gerais state, Brazil. The serpentarium is registered in the Brazilian Institute of Environment and Renewable Natural Resources - IBAMA (n. 301286).

\section{Competing interests}

The authors declare that there are no competing interests.

\section{Authors' contributions}

LEC, RSR and JBF contributed to the collection, analysis and interpretation of data, writing of the manuscript and its final approval. RSR participated in the collection, analysis and interpretation of data, critical reading of the manuscript and its final approval. FPPF and FHS contributed to the collection of data concerning the cDNA library and hyaluronidase cloning, critical reading of the manuscript and its final approval. MIHB and VMR were involved in critical contribution to analysis and interpretation of data, critical reading of the manuscript and its final approval. All authors read and approved the final manuscript.

\section{Acknowledgments}

The authors gratefully acknowledge the financial support of Conselho Nacional de Desenvolvimento Científico e Tecnológico (CNPq), Universidade Federal de Uberlândia (UFU), Fundação de Amparo à Pesquisa dos Estados de Minas Gerais (FAPEMIG) and Coordenação de Aperfeiçoamento de Pessoal de Nível Superior (CAPES), Brazil. We also thank the technical support of Genetic and Evolution Department from Federal University of São Carlos, Brazil.

\section{Author details}

1 Instituto de Genética e Bioquímica, Universidade Federal de Uberlândia, Uberlândia, MG CEP 384000-902, Brasil. 'Department of Physics and Chemistry, School of Pharmaceutical Sciences, University of São Paulo (USP), Ribeirão Preto, São Paulo State, Brazil. ${ }^{3}$ Department of Genetics and Evolution, Federal University of São Carlos (UFSCar), São Carlos, São Paulo State, Brazil. ${ }^{4}$ National Institute of Sciences and Technology on Nanobiopharmaceutics (INCT), Federal University of Minas Gerais (UFMG), Belo Horizonte, Minas Gerais State, Brazil.

Received: 17 January 2014 Accepted: 30 May 2014

Published: 10 June 2014

\section{References}

1. Meyer K: Hyaluronidases. In The Enzymes. Volume 5. Edited by Boyer PD. New York: Academic Press; 1971:307-320.

2. Menzel EJ, Farr C: Hyaluronidase and its substrate: biochemistry, biological activities and therapeutic uses. Cancer Lett 1998, 131(1):3-11.

3. Csóka AB, Scherer SW, Stern R: Expression analysis of six paralogous human hyaluronidase genes clustered on chromosomes $3 p 21$ and $7 q 31$. Genomics 1999, 60(3):356-361.

4. Duran-Reynalds F: Exaltation de l'activité de virus vaccinal par les extraits de certains organs. Compt Rend Soc Biol 1928, 9:6-7.

5. Duran-Reynalds F: Studies on a certain spreading factor existing in bacteria and its significance for bacterial invasiveness. J Exp Med 1933, 58(2):161-181.

6. Girish KS, Jagadeesha DK, Rajeev KB, Kemparaju K: Snake venom hyaluronidase: an evidence for isoforms and extracellular matrix degradation. Mol Cell Biochem 2002, 240:105-110.

7. Shashidharamurthy R, Jagadeesha DK, Girish KS, Kemparaju K: Variation in biochemical and pharmacological properties of Indian cobra (Naja naja naja) venom due to geographical distribution. Mol Cell Biochem 2002, 229:93-101.

8. Girish KS, Kemparaju K: Inhibition of Naja naja venom hyaluronidase: Role in the management of poisonous bite. Life Sci 2006, 78(13):1433-1440.

9. de Sá VK, Canavez FC, Silva IA, Srougi M, Leite KRM: Isoforms of hyaluronidases can be a predictor of a prostate cancer of good prognosis. Urol Oncol 2009, 27(4):377-381.

10. Harrison RA, Ibison F, Wilbrahan D, Wagstaff SC: Identification of CDNA enconding viper venom hyaluronidases: cross-generic sequence conservation of full-length and unusually short variant transcripts. Gene 2007, 392(1-2):22-33.

11. Kolarich D, Loos A, Léonard R, Mach L, Marzban G, Hemmer W, Altmann F: A proteomic study of the major allergens from yellow jacket venoms. Proteomics 2007, 7(10):1615-1623.

12. Girish KS, Shashidharamurthy R, Nagaraju S, Gowda TV, Kemparaju K: Isolation and characterization of hyaluronidase a "spreading factor" from Indian cobra (Naja naja) venom. Biochimie 2004, 86(3):193-202.

13. Wagstaff SC, Sanz L, Juárez P, Harrison RA, Calvete JJ: Combined snake venomics and venom gland transcriptomic analysis of the ocellated carpet viper. Echis ocellatus. J Proteomics 2009, 71(6):609-623.

14. Wahby AF, el SM M, El-Mezayen HA, Salama WH, Abdel-Aty AM, Fahmy AS: Egyptian horned viper Cerastes cerastes venom hyaluronidase: Purification, partial characterization and evidence for its action as a spreading factor. Toxicon 2012, 60(8):1380-1399.

15. Bordon KC, Perino MG, Giglio JR, Arantes EC: Isolation, enzymatic characterization and antiedematogenic activity of the first reported rattlesnake hyaluronidase from Crotalus durissus terrificus venom. Biochimie 2012, 94(12):2740-2748.

16. Rotenberg D, Bamberger ES, Kochva E: Studies on ribonucleic acid synthesis in the venom glands of Vipera palaestinae. Biochem J 1971, 121(4):609-612. 
17. Rodrigues RS, Boldrini-França J, Fonseca FP, de la Torre P, Henrique-Silva F, Sanz L, Calvete JJ, Rodrigues VM: Combined snake venomics and venom gland transcriptomic analysis of Bothropoides pauloensis. J Proteomics 2012, 75(9):2707-2720.

18. Altschul SF, Madden TL, Schäffer AA, Zhang J, Zhang Z, Miller W, Lipman DJ: Gapped BLAST and PSI-BLAST: a new generation of protein database search programs. Nucleic Acids Res 1997, 25(17):3389-3402.

19. Bendtsen D, Nielsen H, von Heijne G, Brunak S: Improved prediction of signal peptides: SignalP 3.0. J Mol Biol 2004, 340(4):783-795.

20. Gasteiger E, Hoogland C, Gattiker A, Duvaud S, Wilkins MR, Appel RD, Bairoch A: Protein Identification and Analysis Tools on the ExPASy Server. In The Proteomics Protocols Handbook. Edited by Walker JM. New Jersey: Humana Press; 2005:571-607

21. Tamura K, Dudley J, Nei M, Kumar S: MEGA4: Molecular Evolutionary Genetics Analysis (MEGA) software version 4.0. Mol Biol Evol 2007, 24(8):1596-1599.

22. Xu X, Wang XS, Xi XT, Liu J, Huang JT, Lu ZX: Purification and partial characterization of hyaluronidase from five pace snake (Agkistrodon acutus) venom. Toxicon 1982, 20(6):973-981.

23. Pukrittayakamee S, Warrell DA, Desakorn V, McMichael AJ, White NJ, Bunnag $D$ : The hyaluronidase activities of some Southeast Asian snake venoms. Toxicon 1988, 26(7):629-637.

24. Kudo K, Tu AT: Characterization of hyaluronidase isolated from Agkistrodon contortrix contortrix (Southern copperhead) venom. Arch Biochem Biophys 2001, 386(2):154-162

25. Fox JW: A brief review of the scientific history of several lesser-known snake venom proteins: I-amino acid oxidases, hyaluronidases and phosphodiesterases. Toxicon 2013, 62:75-82.

26. Ng HC, Ranganathan S, Chua KL, Khoon EK: Cloning and molecular characterization of the first aquatic hyaluronidase, SFHYA1, from the venom of stonefish (Synanceja horrida). Gene 2005, 346:71-81.

27. Li MW, Yudin Al, Robertson KR, Cherr GN, Overstreet JW: Importance of glycosylation and disulfide bonds in hyaluronidase activity of macaque sperm surface PH-20. J Androl 2002, 23(2):211-219.

28. Ronin C, Granier C, Caseti C, Bouchilloux S, Van Rietschoten J: Synthetic substrates for thyroid oligosaccharide transferase. Effects of peptide chain length and modifications in the Asn-Xaa-Thr-region. Eur J Biochem 1981, 118(1):159-164.

29. Cherr GN, Yudin Al, Overstreet JW: The dual functions of GPI-anchored PH-20: hyaluronidase and intracellular signaling. Matrix Bio/ 2001, 20 (8):515-525.

30. Fry BG: From genome to "venome": molecular origin and evolution of the snake venom proteome inferred from phylogenetic analysis of toxin sequences and related body proteins. Genome Res 2005, 15(3):403-420.

31. Fry BG, Scheib $H$, van der Weerd $L$, Young B, McNaughtan J, Ramjan SF, Vidal N, Poelmann RE, Norman JA: Evolution of an arsenal: structural and functional diversification of the venom system in the advanced snakes (Caenophidia). Mol Cell Proteomics 2008, 7(2):215-246.

32. Zhang L, Bharadwaj AG, Casper A, Barkley J, Barycki JJ, Simpson MA: Hyaluronidase activity of human hyal 1 requires active site acidic and tyrosine residues. J Biol Chem 2009, 284(14):9433-9442.

33. Arming S, Strobl B, Wechselberger C, Kreil G: In vitro mutagenesis of $\mathrm{PH}-20$ hyaluronidase from human sperm. Eur J Biochem 1997, 247(3):810-814.

34. Davies GJ, Dauter M, Brzozowski AM, Bjornvad ME, Andersen KV, Schülein M: Structure of the Bacillus agaradherans family 5 endoglucanase at $1.6 \mathrm{a}$ and its cellobiose complex at $2.0 \AA$ resolution. Biochemistry 1998, 37 (7):1926-1932.

35. Divne C, Stahlberg J, Teeri TT, Jones TA: High-resolution crystal structures reveal how a cellulose chain is bound in the $50 \mathrm{~A}$ long tunnel of cellobiohydrolase I from Trichoderma reesei. J Mol Biol 1998, 275(2):309-325.

36. Marković-Housley K, Miglierini G, Soldatova L, Rizkallah PJ, Müller U, Schirmer T: Crystal structure of hyaluronidase, a major allergen of bee venom. Structure 2000, 8(10):1025-1035

37. Botzki A, Rigden DJ, Braun S, Nukui M, Salmen S, Hoechstetter J, Bernhardt G, Dove S, Jedrzejas MJ, Buschauer A: L-Ascorbic acid 6-hexadecanoate, a potent hyaluronidase inhibitor. X-ray structure and molecular modeling of enzyme-inhibitor complexes. J Biol Biochem 2004, 279(44):45990-45997.

38. Chao KL, Muthukumar L, Herzberg O: Structure of human hyaluronidase-1, a hyaluronan hydrolyzing enzyme involved in tumor growth and angiogenesis. Biochemistry 2007, 46(23):6911-6920.
39. Henrissat B, Callebaut I, Fabrega S, Lehn P, Mornon JP, Davies G: Conserved catalytic machinery and the prediction of a common fold for several families of glycosyl hydrolases. Proc Natl Acad Sci U S A 1995, 92(15):7090-7094

40. Fry BG, Roelants $K$, Champagne DE, Scheib H, Tyndall JD, King GF, Nevalainen TJ, Norman JA, Lewis RJ, Norton RS, Renjifo C, de la Vega RC: The toxicogenomic multiverse: convergent recruitment of proteins into animal venoms. Annu Rev Genomics Hum Genet 2009, 10:483-511.

41. Valenzuela A, Talavera D, Orozco M, de la Cruz X: Alternative splicing mechanisms for the modulation of protein function: conservation between human and other species. J Mol Biol 2004, 335(2):495-502.

42. Stamm S, Ben-Ari S, Rafalska I, Tang Y, Zhang Z, Toiber D, Thanaraj TA, Soreq $\mathrm{H}$ : Function of alternative splicing. Gene 2005, 344:1-20.

43. Junker N, Latini S, Petersen LN, Kristjansen PE: Expression and regulation patterns of hyaluronidases in small cell lung cancer and glioma lines. Oncol Rep 2003, 10(3):609-616.

44. Lokeshwar VB, Schroeder GL, Carey RI, Soloway MS, lida N: Regulation of hyaluronidase activity by alternative mRNA splicing. J Biol Chem 2002, 277(37):33654-33663.

45. Lokeshwar VB, Estrella V, Lopez L, Kramer M, Gomez P, Soloway MS, Lokeshwar BL: HYAL1-v1, an alternatively spliced variant of HYAL1 hyaluronidase: a negative regulator of bladder cancer. Cancer Res 2006, 66(23):11219-11227.

46. Harris RC, Chung E, Coffey RJ: EGF receptor ligands. Exp Cell Res 2003, 284(1):2-13.

47. Wouters MA, Rigoutsos I, Chu CK, Feng LL, Sparrow DB, Dunwoodie SL: Evolution of distinct EGF domains with specific functions. Protein Sci 2005, 14(4):1091-1103.

48. Futuyma DJ: Biologia Evolutiva. 2nd edition. Ribeirão Preto: Sociedade Brasileira de Genética/CNPq; 1992

49. Feng L, Gao R, Meng J, Gopalakrishnakone P: Cloning and molecular characterization of BmHYA1, a novel hyaluronidase from the venom of Chinese red scorpion Buthus martensi karsch. Toxicon 2010, 56(3):474-479.

doi:10.1186/1678-9199-20-25

Cite this article as: Castanheira et al:: Molecular cloning of a hyaluronidase from Bothrops pauloensis venom gland. Journal of Venomous Animals and Toxins including Tropical Diseases 2014 20:25.

\section{Submit your next manuscript to BioMed Central and take full advantage of:}

- Convenient online submission

- Thorough peer review

- No space constraints or color figure charges

- Immediate publication on acceptance

- Inclusion in PubMed, CAS, Scopus and Google Scholar

- Research which is freely available for redistribution 